Mathématiques et sciences humaines
Mathematics and social sciences

189 | Printemps 2010

Varia

\title{
Guilbaud's 1952 theorem on the logical problem of aggregation
}

Le théorème de Guilbaud de 1952 sur le problème logique de l'agrégation

Daniel Eckert et Bernard Monjardet

\section{(2) OpenEdition}

12 Journals

Édition électronique

URL : http://journals.openedition.org/msh/11677

DOI : $10.4000 / \mathrm{msh} .11677$

ISSN : 1950-6821

Éditeur

Centre d'analyse et de mathématique sociales de l'EHESS

Édition imprimée

Date de publication : 5 janvier 2010

Pagination : 19-35

ISSN : 0987-6936

\section{Référence électronique}

Daniel Eckert et Bernard Monjardet, « Guilbaud's 1952 theorem on the logical problem of

aggregation », Mathématiques et sciences humaines [En ligne], 189 | Printemps 2010, mis en ligne le 22 juin 2010, consulté le 23 juillet 2020. URL : http://journals.openedition.org/msh/11677 ; DOI : https:// doi.org/10.4000/msh. 11677

(c) École des hautes études en sciences sociales 


\title{
GUILBAUD'S 1952 THEOREM ON THE LOGICAL PROBLEM OF AGGREGATION $^{1}$
}

\author{
Daniel ECKERT ${ }^{2}$, Bernard MONJARDET ${ }^{3}$
}

\section{RÉSUMÉ - Le théorème de Guilbaud de 1952 sur le problème logique de l'agrégation} Dans un article publié en 1952, peu après la publication du théorème d'impossibilité d'Arrow, le mathématicien français Georges-Théodule Guilbaud a obtenu un résultat dictatorial pour le problème logique de l'agrégation, anticipant ainsi la théorie abstraite de l'agrégation et celle de l'agrégation des jugements. Nous donnons une reconstruction de la preuve du théorème de Guilbaud, qui présente aussi un intérêt technique, puisqu'elle peut être vue comme le premier emploi des ultrafiltres en théorie du choix social.

MOTS-CLÉS - Agrégation, Agrégation des jugements, Connecteurs logiques, Jeu simple, Ultrafiltre

SUMMARY - In a paper published in 1952, shortly after the publication of Arrow's celebrated impossibility result, the French mathematician Georges-Théodule Guilbaud has obtained a dictatorship result for the logical problem of aggregation, thus anticipating the literature on abstract aggregation theory and judgment aggregation. We reconstruct the proof of Guilbaud's theorem, which is also of technical interest, because it can be seen as the first use of ultrafilters in social choice theory.

KEYWORDS - Aggregation, Judgment aggregation, Logical connectives, Simple game, Ultrafilter

\section{INTRODUCTION}

In 1952, one year after the publication of Arrow's book Social choice and individual values, the French mathematician Georges-Théodule Guilbaud (1912-2008) published a paper called Les théories de l'intérêt général et le problème logique de l'agrégation (Theories of the general interest and the logical problem of aggregation $^{4}$ ). In our paper we will describe the historical background of this paper that contained several sharp views on the problem of aggregation [Monjardet, 2010]. But, we will concentrate on Guilbaud's logical formalization of this problem and on his dictatorship result on the aggregation of logically interconnected propositions.

\footnotetext{
${ }^{1}$ A first version of this paper was presented at the major conference of the ADRES New Developments in Social Choice and Welfare Theories: A Tribute to Maurice Salles, June 10-12, 2009.

${ }^{2}$ Institut für Finanzwissenschaft, Universität Graz, daniel.eckert@uni-graz.at

${ }^{3}$ Centre d'Économie de la Sorbonne, Université Paris 1 and CAMS, EHESS, 54, boulevard Raspail 75270 Paris cedex 06, Bernard.Monjardet@univ-paris1.fr

${ }^{4}$ For an unabriged english translation of Guilbaud's paper see [Guilbaud, 2008], a drastically abridged translation [Guilbaud, 1966] had remained almost unnoticed [Monjardet, 2008(a)].
} 
There are at least two reasons to come back to this not enough known material. First, it appears as the first attempt to build a general abstract theory of aggregation based here on a logical approach. So, it prefigured works like, one one hand those of Wilson [1975], Rubinstein and Fishburn [1986] or Leclerc and Monjardet [1994], and, on the other hand those of the theory of judgment aggregation [List, Puppe, 2009; List, Polak, 2010]. Second, it appears as the very first application of an ultrafilter proof strategy to get an Arrovian impossibility theorem. Then, it prefigures the use of such a proof technique in works like those of Kirman and Sondermann [1972] or Hansson [1976] in social choice theory [Monjardet 1983] or those more recent of Gärdenfors [2006], Dietrich and Mongin [2010] (especially for the infinite case), Herzberg [2008] (for the use of ultraproducts), Daniels and Pacuit [2009] or Klamler and Eckert [2009] (for a simple proof of a central result) in judgment aggregation.

Unfortunately, Guilbaud gave only what he called an "intuitive" proof of his main result $(571 \text {, fn. } 1 / 48 \text {, fn. 101 })^{5}$. In the following two Sections we give a reconstruction of Guilbaud's main result and an explicit ultrafilter proof of his theorem. Indeed, Guilbaud uses only implicitly the concept of ultrafilter for reasons given in Section 4 where we provide historical details on the genesis of his theorem. In Section 5 we set this theorem in the context of the recent literature on judgment aggregation.

\section{GUILBAUD'S THEOREM}

Explicitly following the algebraic approach to logic underlying modern mathematical logic (534 ff./23 ff.), Guilbaud formulates the "logical problem of aggregation" in the algebraic framework of binary valuations of a set of sentences in propositional logic. In particular, he considers "each individual opinion as a system of judgments, that is, of affirmations or negations, of acceptances or refusals, of a certain number of simple propositions" (535/23). Logical connections between these propositions directly translating into restrictions on the set of admissible valuations $(537 / 25)$, Guilbaud identifies the logical problem of aggregation as the problem of finding a rule which assigns to each profile of individual opinions a logically consistent "collective opinion", i.e. an admissible valuation. Thus, Guilbaud's approach is entirely consistent with the literature on abstract aggregation theory (see [Wilson, 1975], [Rubinstein, Fishburn, 1986] and, for a survey, [Day, McMorris, 2003]), and on judgment aggregation (see especially [Dokow, Holzman, 2010]) in the framework of which it can easily be reconstructed. In fact, Guilbaud can be seen as a precursor of both strands of literature as we will show in the discussion in Section 5.

Let $P=\left\{p_{1}, \ldots, p_{j}, \ldots, p_{m}\right\}$ be an indexed set of $m$ sentences in propositional logic, which constitutes the agenda of the collective decision problem. For simplicity, the agenda will be identified with the index set $\{1, \ldots, j, \ldots, m\}$ of issues and a proposition $p_{j}$ will be identified with the $j$-th issue. A valuation of the agenda $P$ is a map $P \rightarrow\{0,1\}$ which assigns a truth value to any proposition in the agenda. Algebraically, it is thus a vector $x=\left(x_{1}, \ldots, x_{j}, \ldots, x_{m}\right) \in\{0,1\}^{P}$.

\footnotetext{
${ }^{5} \operatorname{In}(571$, fn. $1 / 48$, fn. 101), 571 is the corresponding page in Guilbaud's [1952] original paper, 48 the corresponding page in its english translation [Guilbaud, 2008], and fn. 1 (respectively, 101) refers to footnote 1 (respectively, 101).
} 
Given a set $N=\{1, \ldots, i, \ldots, n\}$ of individuals, a profile is a map $N \rightarrow\{0,1\}^{P}$ and it is denoted by $\underline{x}=\left(\underline{x}^{1}, \ldots, \underline{x}^{i}, \ldots, \underline{x}^{n}\right) \in\left(\{0,1\}^{P}\right)^{N}$, where, for every $i \in N$, $\underline{x}^{i}=\left(\underline{x}_{1}^{i}, \ldots \underline{x}_{j}^{i}, \ldots, \underline{x}_{m}^{i}\right)$ is the valuation of $P$ by individual $i$.

An aggregation rule is then a map $f:\left(\{0,1\}^{P}\right)^{N} \rightarrow\{0,1\}^{P}$.

Clearly, if the propositions in the agenda are logically interconnected, not all valuations are admissible (logically consistent). E.g. for an agenda $P=\left\{p_{1}, p_{2}\right\}$ where $p_{1}$ implies $p_{2}$ the valuation $(1,0)$ is inadmissible. In fact to define logical connections between the propositions of an agenda $P$ comes back to define the set $X \subseteq\{0,1\}^{P}$ of admissible valuations of the propositions in $P$. In particular, as is familiar from the use of truth tables, the sixteen elements of the power set of $\{0,1\}^{2}$ define the sixteen logical connections between two propositions $p_{1}$ and $p_{2}$. E.g. the set $X=\{(0,0),(0,1),(1,1)\}$ of admissible valuations defines precisely the material implication $p_{1} \rightarrow p_{2}$.

For a given agenda $P$, the subdomain of admissible valuations $X \subseteq\{0,1\}^{P}$ is closed under the aggregation rule $f$ if $f\left(X^{N}\right) \subseteq X$, that is if the aggregation rule does not assign an inadmissible collective valuation to a profile of admissible individual valuations. Guilbaud calls "Condorcet Effect" (537/25) the fact that a particular subdomain may not be closed under the aggregation rule. Then, and in particular under majority voting, the collective outcome may be an inadmissible valuation, i.e. a valuation which could not have been the opinion of any one $(565 / 44)$. Thus, Guilbaud formulates his "logical problem of aggregation" as the problem of identifying those aggregation rules which guarantee closure of relevant subdomains, i.e. domains that correspond to an agenda of logically interconnected propositions (the domain $X=\{0,1\}^{P}$ corresponding to an agenda of logically completely independent propositions being trivially closed under any aggregation rule). In particular, an aggregation rule is called acceptable by Guilbaud $(559 / 40)$, if for every agenda $P$ the corresponding subdomain of admissible valuations $X \subseteq\{0,1\}^{P}$ is closed.

Similarly to the social choice literature, Guilbaud stresses the significance of independence and neutrality conditions for aggregation rules. In fact, he claims that the collective valuation of any issue should only depend on the individual valuations of that issue and that this pattern of dependence should be the same for all issues, a property known as systematicity in the literature on judgment aggregation.

However, unlike Arrow in his formulation of the condition of independence of irrelevant alternatives, Guilbaud does not justify these invariance properties by the requirement that the availability of a third alternative should not alter the choice between any two alternatives but rather justifies the strong condition of systematicity by the second order problem of collectively identifying and establishing any relevant additional information to the individual valuations of a given issue. In Guilbaud's view, this implicitly defines new issues and thus, requires the introduction of additional "ideal' voters (...) whose task is to qualify the ballot by their answers" (569/46).

Let $\underline{x} \in\left(\{0,1\}^{P}\right)^{N}$ be a profile, $j$ an issue and $v \in\{0,1\}$ a truth value; the subset of individuals

$$
\underline{x}_{j}(v):=\left\{i \in N: x_{j}^{i}=v\right\}
$$


is the set of individuals that assign the valuation $v$ to the issue $j$. Denoting for any aggregation rule $f:\left(\{0,1\}^{P}\right)^{N} \rightarrow\{0,1\}^{P}$ by $f_{j}$ the $j$-th component of $f$, i.e. the function $f_{j}:\left(\{0,1\}^{P}\right)^{N} \rightarrow\{0,1\}$ that assigns to any profile of individual valuations the social valuation of the issue $j$, the following invariance conditions can be defined.

DEFinition 1. An aggregation rule $f:\left(\{0,1\}^{P}\right)^{N} \rightarrow\{0,1\}^{P}$ is independent if for any issue $j \in P$, any valuation $v \in\{0,1\}$, and for all profiles $\underline{x}, \underline{x}^{\prime} \in\left(\{0,1\}^{P}\right)^{N}$

$$
f_{j}(\underline{x})=v \Rightarrow\left[\underline{x}_{j}(v)=\underline{x}_{j}^{\prime}(v) \Rightarrow f_{j}\left(\underline{x}^{\prime}\right)=v\right] .
$$

An aggregation rule $f:\left(\{0,1\}^{P}\right)^{N} \rightarrow\{0,1\}^{P}$ is neutral if for all issues $k, l \in P$,

$$
f_{k}=f_{l} \text {. }
$$

An aggregation rule is systematic if it is independent and neutral, i.e. if for all issues $k, l \in P$, for all valuations $v, v^{\prime} \in\{0,1\}$, and for all profiles $\underline{x}, \underline{x}^{\prime} \in\left(\{0,1\}^{P}\right)^{N}$

$$
f_{k}(\underline{x})=v \Rightarrow\left[\underline{x}_{k}(v)=\underline{x}_{l}^{\prime}\left(v^{\prime}\right) \Rightarrow f_{l}\left(\underline{x}^{\prime}\right)=v^{\prime}\right] .
$$

Independence means that the social valuation of any given issue only depends on the individual valuations of the very same issue. Systematicity makes the further neutrality requirement that this pattern of dependence be the same for all issues.

Given an aggregation rule $f:\left(\{0,1\}^{P}\right)^{N} \rightarrow\{0,1\}^{P}$, let us say that a subset of individuals $U=\underline{x}_{j}(v)$ is a winning coalition for the issue $j \in P$, the valuation $v \in\{0,1\}$ and the profile $\underline{x} \in\left(\{0,1\}^{P}\right)^{N}$ if $f_{j}(\underline{x})=v$. Then, observe that when the aggregation rule $f$ is independent the set $U$ is also a winning coalition for $j$, $v$ and any profile $\underline{x}^{\prime} \in\left(\{0,1\}^{P}\right)^{N}$ such that $\underline{x}_{j}^{\prime}(v)=\underline{x}_{j}(v)$. Thus, an independent aggregation rule can be characterised by identifying for any issue $j \in P$ and any valuation $v \in\{0,1\}$ the family $\mathcal{W}_{j}^{v}=\left\{U \in 2^{N}: \underline{x}_{j}(v)=U \Rightarrow f_{j}(\underline{x})=v\right\}$, i.e. the family of all coalitions that are winning for a given issue and a given valuation. One says that these families of winning coalitions are induced by the aggregation rule $f$.

Observe that for any issue $j \in P$, the families $\mathcal{W}_{j}^{1}$ and $\mathcal{W}_{j}^{0}$ are co-dual in the sense that for any valuation $v \in\{0,1\}$ and any coalition $U \in 2^{N}, U \in \mathcal{W}_{j}^{v}$ if and only if $N \backslash U \notin \mathcal{W}_{j}^{1-v}$.

Systematicity then simply translates into the condition $\mathcal{W}_{k}^{v}=\mathcal{W}_{l}^{v}=\mathcal{W}^{v}$ for all issues $k, l \in P$ and any given valuation $v \in\{0,1\}$. So, when the aggregation rule $f$ is systematic, there exists two families $\mathcal{W}^{0}$ and $\mathcal{W}^{1}$ of subsets of $N$ such that for any issue $j \in P$, for any valuation $v \in\{0,1\}$, and for any profile $\underline{x} \in\left(\{0,1\}^{P}\right)^{N}$,

$$
f_{j}(\underline{x})=v \text { if and only if } \underline{x}_{j}(v) \in \mathcal{W}^{v} .
$$

In other words, a winning coalition for a valuation $v \in\{0,1\}$, i.e. a member of $\mathcal{W}^{v}$, is a winning coalition for any issue.

The central part of Guilbaud's argumentation consists in showing how the acceptability condition of closure of all the subdomains of admissible valuations under an aggregation rule translates into conditions on its induced families of winning coalitions, which ultimately amount to a dictatorship. 
DEFinition 2. An aggregation rule $f:\left(\{0,1\}^{P}\right)^{N} \rightarrow\{0,1\}^{P}$ is dictatorial (or is a dictatorship) if there exists an individual $i \in N$ such that $\mathcal{W}_{k}^{v}=\mathcal{W}_{l}^{v}=\{U \in$ $\left.2^{N}: i \in U\right\}$ for all issues $k, l \in P$ and any valuation $v \in\{0,1\}$.

Observe that this definition is equivalent to the usual one in terms of the projection of the space of profiles on one of its components, i.e. the characteristics of a particular individual, which then is the dictator

One can now state Guilbaud's theorem:

THEOREM 1 (Guilbaud, 1952). A systematic aggregation rule $f:\left(\{0,1\}^{P}\right)^{N} \rightarrow$ $\{0,1\}^{P}$ for an agenda with more than a single pair of propositions is acceptable (i.e. for any $X \subseteq\{0,1\}^{P} X$ is closed under $f$ ) if and only if it is dictatorial.

We will give Guilbaud's proof of this theorem below. For his demonstration Guilbaud establishes and proves several results about the induced families of winning coalitions. In particular, he establishes the following properties of winning coalitions for systematic aggregation rules.

Definition 3. A coalition $U \in 2^{N}$ is efficient if $U \in W^{v}$ implies $U \in W^{1-v}$ for any valuation $v \in\{0,1\}$, i.e. if it is winning for both valuations of any issue.

The fact that the winning coalitions induced by systematic aggregation rule $f:\left(\{0,1\}^{P}\right)^{N} \rightarrow\{0,1\}^{P}$ are efficient means that $\mathcal{W}^{0}=\mathcal{W}^{1}=\mathcal{W}$, i.e. that such a rule is given for any issue $j \in P$, any valuation $v \in\{0,1\}$, and for any profile $\underline{x} \in\left(\{0,1\}^{P}\right)^{N}$ by

$$
f_{j}(\underline{x})=v \text { if and only if } \underline{x}_{j}(v) \in \mathcal{W} \text {. }
$$

The other important property of winning coalitions shown by Guilbaud is their monotonicity property of closure under supersets. Since this property characterises the families of coalitions known as simple games, it allows Guilbaud to explicitly apply this concept to the analysis of acceptable systematic aggregation rules ${ }^{6}$. Guilbaud shows also other properties - given below - of the simple games induced by systematic aggregation rules.

DEFINITION 4. A simple game on the set $N$ of individuals is a collection $\mathcal{W} \subseteq 2^{N}$ of subsets of $N$ such that for all $U, V \in 2^{N}$, if $U \in \mathcal{W}$ and $U \subset V$, then $V \in \mathcal{W}$.

A simple game is proper if for any $U \in 2^{N}, U \in \mathcal{W} \Rightarrow N \backslash U \notin \mathcal{W}$. A simple game is strong if for any $U \in 2^{N}, U \notin \mathcal{W} \Rightarrow N \backslash U \in \mathcal{W}$.

Finally, when a (systematic) aggregation rule is defined by a set of (efficient) winning coalitions forming a proper and strong simple game Guilbaud says that it is a rule of majority "in the broad sense" (561/41), as it generalizes the partition

\footnotetext{
${ }^{6}$ Guilbaud quotes von Neumann and Morgenstern's [1944] book where simple games are defined. Observe nevertheless that von Neumann and Morgenstern's definition corresponds to what is now called a proper and strong simple game, and excludes what they call the trivial case where $\mathcal{W}=\left\{U \in 2^{N}: i \in U\right\}$ for some $i \in N$, i.e. precisely a dictatorial situation.
} 
of the sets of coalitions into winning and non-winning coalitions that any majority threshold establishes. Intuitively, this is also the reason for the applicability of the ultrafilter concept which aims precisely at partitioning a power set into "large" and "small" subsets.

Guilbaud establishes his theorem with the help of the following lemma:

LEMMA 1 (Guilbaud, 1952). A systematic aggregation rule is acceptable for any pair of propositions $\{k, l\} \subseteq P$ and for any agenda $P$ if and only if it is a rule of majority in the broad sense, i.e. if there exists a proper and strong simple game $\mathcal{W} \subseteq 2^{N}$ such that for any issue $j \in\{k, l\}$, any valuation $v \in\{0,1\}$ and any profile $\underline{x} \in\left(\{0,1\}^{P}\right)^{N}$

$$
f_{j}(\underline{x})=v \text { if and only if }\left\{i \in N: \underline{x}_{j}^{i}=v\right\} \in \mathcal{W} \text {. }
$$

In order to prove this lemma Guilbaud first observes that since the aggregation rule $f:\left(\{0,1\}^{P}\right)^{N} \rightarrow\{0,1\}^{P}$ is systematic, i.e. the function $f_{j}:\left(\{0,1\}^{P}\right)^{N} \rightarrow\{0,1\}$ does not depend on the valuation of other issues than $j$ and is the same for each issue $j \in P$, it is sufficient to consider a single function from $\{0,1\}^{N}$ into $\{0,1\}$ which, in a slight abuse of notation, we still denote by $f$.

Guilbaud proves his lemma by establishing necessary and sufficient conditions for the preservation of any logical connection between two propositions $p_{1}$ and $p_{2}$ by a systematic aggregation rule. He starts by considering the four logical connectives which are determined by all the three element subsets of the power set of $\{0,1\}^{2}$. These are the material implication (for which $(1,0)$ is inadmissible), the converse implication (for which $(0,1)$ is inadmissible), the alternative denial (NAND) and the disjunction (for which $(1,1)$ resp. $(0,0)$ are inadmissible).

Beginning with the material implication, Guilbaud establishes a necessary and sufficient condition for the preservation of the implication $p_{1} \rightarrow p_{2}$, i.e. the exclusion of the inadmissible valuation $(1,0)$. Observe that if the valuation $(1,0)$ is inadmissible, this implies for all profiles of admissible valuations $\underline{x} \in X^{N}=\left[\{0,1\}^{2} \backslash(1,0)\right]^{N}$ that $\underline{x}_{1}(1)=\left\{i \in N: \underline{x}_{1}^{i}=1\right\} \subseteq \underline{x}_{2}(1)=\left\{i \in N: \underline{x}_{2}^{i}=1\right\}$.

Thus the exclusion of the inadmissible valuation $(1,0)$ requires the avoidance of the following coincidence ("rencontre des deux faits", 558/39) for any profile $\underline{x} \in\left(\{0,1\}^{P}\right)^{N}$

(1) $\underline{x}_{1}(1) \subseteq \underline{x}_{2}(1)$

(2) $f_{1}(\underline{x})=1$ and $f_{2}(\underline{x})=0$, or equivalently, given independence, $\underline{x}_{1}(1) \in \mathcal{W}^{1}$ and $\underline{x}_{2}(0) \in \mathcal{W}^{0}$.

Hence, Guilbaud establishes as a necessary and sufficient condition for the preservation of the implication $p_{1} \rightarrow p_{2}$ the following for all profiles $\underline{x} \in\left(\{0,1\}^{P}\right)^{N}$ :

$$
\text { If } \underline{x}_{1}(1) \in \mathcal{W}^{1} \text { and } \underline{x}_{2}(0) \in \mathcal{W}^{0} \text { then } \underline{x}_{1}(1) \nsubseteq \underline{x}_{2}(1) \text {, }
$$

or, still by independence, and for any coalition $W \in 2^{N}$, if $W \in \mathcal{W}^{1}$, then $W \nsubseteq N \backslash V$ for all $V \in \mathcal{W}^{0}$.

Given the correspondence between logical connectives and sets of admissible valuations $X \subseteq\{0,1\}^{2}$, it is straightforward to see $(559$, fn. $1 / 39$, fn. 89$)$ that to preserve any logical connection between two propositions comes back to satisfy 
the following condition for the exclusion of any valuation $\left\{v, v^{\prime}\right\} \in\{0,1\}^{2}$ in the corresponding set of inadmissible valuations $\{0,1\}^{2} \backslash X$ :

General exclusion COndition. For any inadmissible valuation $\left(v, v^{\prime}\right) \in\{0,1\}^{2}$ and any profile $\underline{x} \in\left(\{0,1\}^{P}\right)^{N}$, if $\underline{x}_{1}(v) \in \mathcal{W}^{v}$ and $\underline{x}_{2}\left(v^{\prime}\right) \in \mathcal{W}^{v^{\prime}}$, then $\underline{x}_{1}(v) \nsubseteq$ $\underline{x}_{2}\left(1-v^{\prime}\right)$,

or, by independence, and for any coalition $W \in 2^{N}$,

if $W \in \mathcal{W}^{v}$, then $W \nsubseteq N \backslash V$ for all $V \in \mathcal{W}^{v^{\prime}}$.

This exclusion condition is thus a necessary and sufficient condition in order that a systematic aggregation rule preserves all the logical connections between two propositions.

The application of this exclusion condition together with other properties readily establishes the following properties of winning coalitions:

To show that all winning coalitions must be efficient (559 f./40), Guilbaud considers two propositions such that $p_{1} \leftrightarrow \neg p_{2}$ and the corresponding valuations are "contradictory", i.e. $\underline{x}_{1}(v)=\underline{x}_{2}(1-v)$ for any valuation $v \in\{0,1\}$ and for any profile $\underline{x} \in\left(\{0,1\}^{P}\right)^{N}$. Clearly, by the exclusion condition, if $\underline{x}_{1}(v)=\underline{x}_{2}(1-v) \in \mathcal{W}^{v}$ then $N \backslash \underline{x}_{2}(1-v) \notin \mathcal{W}^{v}$ and hence by co-duality $\underline{x}_{2}(1-v)=\underline{x}_{1}(v) \in \mathcal{W}^{1-v}$, i.e. any winning coalition for a valuation $v$ is also winning for the valuation $1-v$.

Guilbaud then proceeds to show that the family $\mathcal{W}=\mathcal{W}^{1}=\mathcal{W}^{0}$ of efficient coalitions is closed under supersets, i.e. that $\mathcal{W}$ is a simple game $(560 / 40)$. This follows from the exclusion condition by an easy proof by contradiction: Assume to the contrary that for some winning coalition $W \in \mathcal{W}$ there exists a superset $U$ of $W$ which is not a winning coalition (i.e. $W \subset U$, but $U \notin \mathcal{W}$, and hence $N \backslash U \in \mathcal{W}$ ). The exclusion condition now requires that $N \backslash U \nsubseteq N \backslash W$ which contradicts the assumption that $W \subset U$.

Finally, it follows from efficiency together with co-duality that the induced family of winning coalitions is a strong and proper simple game $(561 / 41)$.

Now, to show that an acceptable systematic aggregation rule for an agenda with at least three propositions is dictatorial, it suffices to show that the strong and simple game $\mathcal{W}$ induced by such an aggregation rule has the form $\mathcal{W}=\left\{U \in 2^{N}: i \in U\right\}$ for some individual $i \in N$ - the dictator.

This is done by Guilbaud by identifying an essential condition for the acceptability of a systematic aggregation rule, the violation of which is responsible for the "Condorcet effect":

DEFINITION 5. A collection $\mathcal{W} \subseteq 2^{N}$ satisfies the intersecting triple property if for all $U, V, W \in \mathcal{W}, U \cap V \cap W \neq \emptyset$.

Observe that this property is equivalent to the condition that the Nakamura number $^{7}$ of the collection $\mathcal{W}$ be strictly larger than three [Monjardet, 2003].

\footnotetext{
${ }^{7}$ The Nakamura number of a collection $\mathcal{W} \subseteq 2^{N}$ of subsets of $N$ is the cardinality of the smallest subset of $\mathcal{W}$ with empty intersection.
} 
This condition is also intuitively very plausible as its violation directly leads to the "Condorcet effect", i.e. to a social outcome that cannot be the valuation of any single individual because it is inadmissible.

Guilbaud proves his theorem in three steps (565-567/43-45):

(i) The family $\mathcal{W}$ of winning coalitions satisfies the intersecting triple property.

Indeed, consider any inadmissible valuation $\left(v_{k}, v_{l}, v_{m}\right)$ of three propositions $p_{k}, p_{l}, p_{m} \in P$. Unless this intersection property holds, one can take three coalitions with empty intersection and construct a profile such that $\left\{\underline{x}_{k}\left(v_{k}\right), \underline{x}_{l}\left(v_{l}\right), \underline{x}_{m}\left(v_{m}\right)\right\} \subseteq$ $\mathcal{W}$ leading to the inadmissible valuation $\left(v_{k}, v_{l}, v_{m}\right)$.

(ii) The family $\mathcal{W}$ is closed under intersection.

First, by the intersecting triple property, the intersection of any two winning coalitions is non empty. Now if the intersection of two winning coalitions $U, V \in \mathcal{W}$ is not a winning coalition, its complement $N \backslash U \cap V$ must be a winning coalition, which in turn implies the existence of three winning coalitions with empty intersection $U \cap V \cap(N \backslash U \cap V)=\emptyset$, a contradiction.

iii) The family of winning coalitions has the form $\mathcal{W}=\left\{U \in 2^{N}: i \in U\right\}$ for some individual $i \in N$, - the dictator.

Since $\mathcal{W}$ is closed under intersection, the intersection $\bigcap_{W \in \mathcal{W}} W$ of all the winning coalitions is a winning coalition and it is the minimal winning coalition. Assume that $\bigcap_{W \in \mathcal{W}} W$ is not a singleton and thus contains a proper subset $S \subset \bigcap_{W \in \mathcal{W}} W$. But this implies $N \backslash S \in \mathcal{W}$ and hence $\left(\bigcap_{W \in \mathcal{W}} W\right) \cap(N \backslash S)=\bigcap_{W \in \mathcal{W}}(W \backslash S) \in \mathcal{W}$ by intersection closure. Thus, $\bigcap_{W \in \mathcal{W}} W$ cannot be a minimal winning coalition unless it is a singleton, which completes the proof of dictatorship of any acceptable aggregation rule for an agenda with at least three propositions.

\section{A SIMPLE ULTRAFILTRER PROOF OF GUILBAUD'S THEOREM}

Guilbaud's own proof only implicitly uses the concept of ultrafilter and we will see in section 4 why he did not explicitly use it. In the following we give an explicit and simple ultrafilter proof of his theorem. We begin by recalling some definitions.

DEFinition 6. A filter on a set $N$ is a collection $\mathcal{W} \subseteq 2^{N}$ of subsets of $N$ such that (i) $N \in \mathcal{W}$ and $\emptyset \notin \mathcal{W}$ (non-triviality)

(ii) if $U \in \mathcal{W}$ and $V \in \mathcal{F}$ then $U \cap V \in \mathcal{W}$ (closure under intersection)

(iii) if $U \in \mathcal{W}$ and $U \subset V$ then $V \in \mathcal{W}$ (closure under supersets).

A filter $\mathcal{W}$ on $N$ is a principal filter if it is a collection $\mathcal{W}=\left\{U \in 2^{N}: S \subseteq U\right\}$ for some non-empty subset $S$ of $N$.

An ultrafilter is a maximal filter, i.e. a filter not strictly contained in another filter.

It is clear that on a finite set $N$ every filter is principal and that in particular it follows that every ultrafilter is a collection $\mathcal{W}=\left\{U \in 2^{N}: i \in U\right\}$ for some $i \in N$ which immediately yields a dictatorship result for families of winning coalitions. 
By the monotonicity property of closure under supersets a filter is also a simple game, which allows to use Monjardet's [1978] characterization of ultrafilters ${ }^{8}$ to obtain the following lemma.

LEMMA 2 (Monjardet, 2003). If a family $\mathcal{W}$ of subsets of a set $N$ is a strong simple game which satisfies the intersecting triple property, it is an ultrafilter.

This yields a particularly simple ultrafilter proof of Guilbaud's theorem.

Proof. From Guilbaud's lemma we know that a family $\mathcal{W} \subseteq 2^{N}$ of winning coalitions which is induced by an acceptable aggregation rule is a strong and proper simple game on $N$. But for a systematic aggregation rule to be acceptable for an agenda with at least three propositions, its induced family of winning coalitions also needs to satisfy the intersecting triple property, and thus, by Monjardet's lemma, is an ultrafilter. Finally, as $N$ is finite, $\mathcal{W}$ is a principal ultrafilter and thus has the form $\{U \subseteq N: i \in U\}$ for some $i \in N$ - the dictator.

\section{HISTORICAL NOTE}

We will succesively examine three points: the genesis of Guilbaud's 1952 paper, the genesis of Guilbaud's theorem on judgment aggregation, its relation to Arrow's theorem and the origins of the ultrafilter proofs in social choice theory.

Guilbaud's theorem on judgment aggregation is contained in his paper Les théories de l'intérêt général et le problème logique de l'agrégation (Theories of the general interest and the logical problem of aggregation). In order to understand the genesis of this paper we must put together some biographical and scientific facts ${ }^{9}$. Guilbaud, after his studies of mathematics at the École Normale Supérieure (1932-1935), was first teacher of in classes of high mathematics ${ }^{10}$ at Metz, Brest then Dijon (19411947). From 1942 to 1947 he also did lectures on the philosophy of sciences at the « Faculté des lettres et sciences humaines » of Dijon. Guilbaud was interested in the use of mathematics in Economics and more generally in Social Sciences. So he read classics like Condorcet, Cournot or Pareto. Gilles-Gaston Granger comes at Dijon in 1943 as professor of philosophy and both begin a friendship where in particular they speak about Condorcet's « Mathématique Sociale » ${ }^{11}$. In 1947 Guilbaud becomes member of the «Institut des Sciences Économiques Appliquées (ISEA) 》 of François Perroux where he works as mathematician, statistician and economist up

\footnotetext{
${ }^{8}$ Monjardet [1978] shows that a collection $\mathcal{W} \subseteq 2^{N}$ of subsets of $N$ is an ultrafilter if and only if it satisfies the intersecting triple property and the property that for any $U \in 2^{N}, U \notin \mathcal{W} \Rightarrow$ $N \backslash U \in \mathcal{W}$. Observe that for collections which are simple games the latter property defines a strong simple game.

${ }^{9}$ Guilbaud died in 2008 and a special issue of Mathématiques et Sciences humaines 183, 2008, contains his biography and his publications (URL: http://www.ehess.fr/revue$\mathrm{msh} /$ recherche.php?numero=183).

${ }^{10}$ These classes prepare students for the competitive examinations allowing the entrance in a «Grande École » like the École Polytechnique or the École Normale Supérieure.

${ }^{11}$ Granger writes in the introduction of his book La mathématique sociale du marquis de Condorcet (Paris, 1956) and which was his Thèse complémentaire pour le doctorat ès lettres: « Je dois à mon collègue et ami G.-Th. Guilbaud, outre des suggestions toujours fécondes, l'idée même d'étudier Condorcet » (p. x).
} 
to 1955. Arrow sends him a preprint of his 1951 book Social Choice and Individual Values. Guilbaud is surprised to see that Arrow doesn't know that the "voting paradox" is due to Condorcet. Meanwhile, Arrow is invited by Perroux at the ISEA to make a presentation of his work. His lecture entitled The rationality principle in collective decisions is given on June 1952 and is published in a special issue of Économie appliquée ${ }^{12}$ devoted to welfare economics and called L'avantage collectif. Guilbaud's paper - certainly motivated by Arrow's coming - is in this same issue.

This paper contains many interesting results and perspectives on aggregation problems ${ }^{13}$. In particular, Guilbaud dragged from the deep oblivion where it had fallen Condorcet's Essai sur l'application de l'analyse à la probabilité des décisions rendues à la pluralité des voix (Paris, 1785) ${ }^{14}$. Indeed, the Essai had been read only by a few contemporaries including the mathematicians Sylvestre-Francois Lacroix and Simon Lhuilier or the politician and historian Pierre Claude Francois Daunou. But later in France reputed mathematicians like Joseph Louis Francois Bertrand in his Calcul des probabilités (Paris, 1888/89) found the book unreadable and anyway without interest, an opinion shared by the main 19th century historian of mathematics Isaac Todhunter who at least had read the Essai ${ }^{15}$. Guilbaud was the first to read again the Essai and to understand the logical problem raised by Condorcet through his sometimes enough confuse probabilistic approach.

Indeed, Condorcet's aim in the Essai is to find the method which maximizes the probability to get the truth when a collectivity must determine it by a voting procedure. The truth can be the culpability or not of a defendant when the collectivity is a court or the best candidate when the collectivity is a recruitment jury. In such cases, the voters must give what Condorcet calls an opinion ( «avis ») on the decision to take. According to Condorcet this opinion can and must always be decomposed in a sequence of answers TRUE or FALSE to binary propositions (equivalently, in a sequence of answers YES or NO to binary questions) ${ }^{16}$. For instance, in the case of candidates, the opinion of a voter can be a (strict) ranking of the candidates and it is decomposed in a sequence of answers to the questions: is candidate A better than candidate B? Now, Condorcet argues that the collective decision must be obtained by taking the opinion resulting of the majority decisions obtained on each question. And he shows a first "paradox": this opinion is not necessarily the opinion obtained by the "plurality" (i.e. the opinion obtaining the greatest number of votes). In fact « en prenant la décision à la pluralité entre les avis à la manière ordinaire, on pourrait adopter l'avis de la minorité » ("by taking the decision between the opinions by the usual plurality method, it would be possible to adopt the minority opinion",

\footnotetext{
${ }^{12}$ Économie appliquée 5(4): 469-484 (October-December 1952).

${ }^{13} \mathrm{An}$ analysis of this paper can be found in [Monjardet, 2005].

${ }^{14}$ For a partial english translation with an introduction into Condorcet's work see [Condorcet, 1994].

${ }^{15}$ In his book $A$ history of the mathematical theory of probability from the time of Pascal to that of Laplace (London, 1865) Todhunter devotes a chapter to a detailed analysis of the Essai but he completely misses the significance of Condorcet's study on the systems of propositions and their possible contradictions ("these results however appear of too little value to detain us any longer", p. 375$)$.

${ }^{16}$ Condorcet's formulation is : « chaque avis est une combinaison de propositions simples et de leurs contradictoires $\gg(E s s a i$, Discours préliminaire, p. 45).
} 
Essai, p. 115). On the other hand, Condorcet observes that the propositions can be linked like in the following example where they are incompatible (Essai, Discours préliminaire, p. 50-51): the first proposition is $\mathrm{p}=$ «il est prouvé que l'accusé est coupable » and the second is $\mathrm{q}=$ 《il est prouvé que l'accusé est innocent ». Now, Condorcet assumes that there are 11 opinions 'p and nonq', 7 opinions 'nonp and q' and 6 opinions 'nonp and nonq'. In this case the opinion having the plurality is 'p and nonq', whereas the opinion obtained by using the majority rule on each of the two propositions is 'nonp and nonq'.

In the case of preferences agregation Condorcet's majority method used on each pairwise comparison between two alternatives leads him to discover the "Condorcet effect" (the paradox of voting): the binary majority preferences do not necessarily yield a ranking, they may lead to a cycle. Now, Guilbaud observes that the problem is more general and has been already encountered for instance in the case of Quetelet's « homme moyen $»^{17}$. The problem occurs each time that one applies like Condorcet - a component-wise method of aggregation of complex objects. It consists first of decomposing complex objects into their simple elements, then of applying to each series of such elements an aggregation operator like the mean or the median (the majority rule comes back to take a median). By definition an essential property of this method is its property of independence: each series of simple elements is aggregated (by the same or by different operators) independently of the other series. Now as soon as the complex objects considered satisfy some relations between their simple elements, the aggregated complex object does not necessarily satisfy these same relations. ${ }^{18}$ In the case of preference aggregation, Arrow proved that the apparition of Condorcet effects is unavoidable in the sense that in order to avoid it one must take a "dictatorial" aggregation procedure or sacrify another desirable property of the aggregation rule. It is certainly the reading of the Essai and of Arrow's result that motivated Guilbaud to consider a more general framework and then to get his dictatorship result on the aggregation of valuations for a set of propositions. However, Guilbaud does not make the claim that his theorem is stronger than Arrow's. In fact, he is well aware that his joint assumption of independence and neutrality is stronger than the Arrovian independence condition, and makes much effort to justify it. But above all, his acceptability condition is even the strongest possible domain condition $^{19}$ and thus much stronger than the Arrovian condition of universal domain which is still restricted to preferences, i.e. to the particular subdomain of admissible valuations for pairwise rankings between alternatives in the case of weak orderings.

On the other hand, Arrow acknowledged Guilbaud's 1952 paper as a "remarkable exposition of the theory of collective choice and the general problem of aggregation" in the second edition of his book [Arrow, 1963, p. 92]. He even seemed ready to

\footnotetext{
${ }^{17}$ See Guilbaud's paper or [Monjardet, 2005] for details.

${ }^{18}$ One can observe that it is exactly this situation which happens in the so-called "doctrinal paradox" (see the following section). Here one has several propositions logically linked and that judges - respecting these links - can find true or false. But when one takes the majority answers to each proposition it is possible to get a result not satisfying the logical links.

${ }^{19}$ In fact, it is possible to strengthen significantly Guilbaud's theorem by considerably weakening his acceptability condition as we will show in a forthcoming paper.
} 
consider the pairwise acceptability condition in lemma 1 as a relaxation of his weak ordering requirement of collective rationality, as the following quotation suggests: "Guilbaud weakens the condition [of Collective Rationality] to require simply avoiding contradictions on two successive decisions (rather than three, when the full force of transitivity comes into play). He then conducts the bulk of his analysis under the assumption that the decision rule between any two alternatives be the same" [Arrow, 1962, p. 100].

This quotation could let think that one can deduce Arrow's theorem from Guilbaud's theorem, what is untrue. But, what is true is that one can use Guilbaud's method of proof to get short proofs of Arrow's theorem [Monjardet, 1969, 1978, 2003].

In the proof of his theorem Guilbaud does not use the term ultrafilter. But it suffices to read his proof to see that "followers of Bourbaki will notice an ultrafilter in the background" as Blau [1979, p. 202] would have said and as it was observed by Monjardet [1969, p. 180]: « Il est alors immédiat que dans l'algèbre de Boole des parties de $N$, la famille [des ensembles décisifs] doit être un filtre maximal » ("then it is immediate that in the Boolean algebra of subsets of $N$, the family [of decisive sets] must be a maximal filter"). In handwritten notes concerning his 1952 paper sent to one of us Guilbaud explains: "I could have pointed out Henri Cartan's filters ${ }^{20}$. But firstly I have found this allusion too pompous and secondly for Cartan the filters were a mean to get rid of 'the plague of countable'. So, it concerns essentially the infinite, what was out of the topic."

It is interesting to observe that the rediscovery of the use of ultrafilter in the proof of Arrow's theorem occured precisely after that Fishburn [1970] noticed that the dictatorship result does not hold in the case of an infinite population of voters (assuming the Axiom of Choice): Then Hansson [1976] in a paper written in 1971, and Kirman and Sondermann [1972] gave an ultrafilter proof of Arrow's theorem by showing that the collection of decisive coalitions induced by a social welfare function satisfying Arrow's other axioms is an ultrafilter. The dictatorship result then immediately follows from the well-known fact that an ultrafilter on a finite set is principal, i.e. the collection of all supersets of some singleton. After this rediscovery ultrafilter proofs were often used for impossibility (or possibility) theorems in social choice theory and in the recent literature on judgment aggregation.

\section{JUDGEMENT AGGREGATION AND GUILBAUD'S THEOREM}

Interestingly, the recent literature on judgment aggregation originates in a paradox which arises in the same legal context of aggregating the opinions of a court of several judges into a collective decision that motivated Condorcet's analysis: the doctrinal paradox [Kornhauser, Sager, 1986]. This paradox owes its name to the logical connections between the issues established by legal doctrine: In particular, in a contract case a defendant is liable $(L)$ if and only if there was a valid contract

\footnotetext{
${ }^{20}$ Henri Cartan was the creator of the notion of filter. See his two 1937 Comptes rendus à l'Académie des Sciences de Paris, «Théorie des filtres» (205, p. 595-598) and « Filtres et ultrafiltres » (205, p. 777-779).
} 
$(C)$ and a material breach $(B)$ of that contract. Thus, the verdict $L$ is equivalent to the conjunction of two propositions.

How easily majority voting can lead to a logically inconsistent outcome is seen from the following table ${ }^{21}$ :

\begin{tabular}{|c|c|c|c|}
\hline & $C$ & $B$ & $L$ \\
\hline Judge 1 & 1 & 1 & 1 \\
\hline Judge 2 & 0 & 1 & 0 \\
\hline Judge 3 & 1 & 0 & 0 \\
\hline Court & 1 & 1 & 0 \\
\hline
\end{tabular}

In fact, the first theorem in the literature on judgment aggregation by List and Pettit [2002] is a straightforward generalization of the doctrinal paradox. This theorem was originally not formulated in the framework of binary valuations, but of the aggregation of judgment sets and uses the stronger property of anonymity instead of non-dictatorship ${ }^{22}$.

THEOREM 2 (List, Pettit, 2002). If for two atomic propositions $p_{k}$, $p_{l}$ the set $\left\{p_{k}, \neg p_{k}, p_{l}, \neg p_{l}, p_{k} \wedge p_{l}, \neg\left(p_{k} \wedge p_{l}\right)\right\}$ is a subset of the agenda $P$ (where $\wedge$ could be replaced by $\vee$ or $\rightarrow$ ), there exists no systematic and anonymous aggregation rule $f: X^{N} \rightarrow\{0,1\}^{P}$ such that the subdomain $X \subseteq\{0,1\}^{P}$ of admissible valuations of the agenda $P$ is closed.

Observe that an equivalent formulation of Guilbaud's theorem is that there exists no systematic and non-dictatorial aggregation rule $f:\left(\{0,1\}^{P}\right)^{N} \rightarrow\{0,1\}^{P}$ under which the subdomain $X \subseteq\{0,1\}^{P}$ of admissible valuations for any agenda $P$ is closed.

Although the non-dictatorship property used by Guilbaud is weaker than the property of anonymity used in List and Pettit's impossibility theorem, Guilbaud's theorem cannot be considered to be stronger, because his acceptability condition is the strongest possible agenda condition: it requires the closure of the subdomain of admissible valuations for any agenda.

Thus the significance of Guilbaud's theorem does not consist in the strength of the result, but in the strength and originality of his approach: Long before Wilson [1975, p. 89] asked the question "whether procedures for aggregating attributes other than preferences are subject to similar restrictions" than Arrow's theorem, which initiated the literature on abstract aggregation theory, and even longer before the recent literature on judgment aggregation Guilbaud generalized Arrow's theorem to the "logical problem of aggregation". Like Rubinstein and Fishburn [1986]

\footnotetext{
${ }^{21}$ In fact, the legal literature on the doctrinal paradox was more interested in the discrepancy between the outcome of majority voting on the premises and the outcome of majority voting on the conclusion.

${ }^{22}$ For the below reformulation of this theorem in the framework of propositional valuations (as well as for a generalization of it) see Pauly and van Hees [2006]. The properties of completeness, consistency, and deductive closure defined for individual and collective judgment sets, i.e. subsets of a set $P$ of propositions then directly translate into the condition that the domain of admissible valuations $X \subseteq\{0,1\}^{P}$ be closed under the aggregation rule.
} 
for abstract aggregation theory and later Dokow and Holzman [2010] for judgment aggregation he formulated this problem in an algebraic framework. But above all, he addressed this problem with the powerful tools of ultrafilters long before they were even used in the theory of preference aggregation.

A classical escape route from Arrovian impossibility results consists in domain restrictions. For particular domain restrictions it can be shown that majority rule never induces a "Condorcet effect". Dietrich and List [2010] provide several domain restrictions that guarantee logically consistent judgments under majority rule. In particular, they show that one can get such domains when the (set of propositions of the) agenda is linearly ordered. This result is similar to Black's single-peakedness condition in preference aggregation. In his paper, Guilbaud devotes several pages (540ff/26ff) to a study of this last condition. He shows that this comes back to define a (partial) order on the set of the pairwise comparisons $x>y$ and that the linear orders satisfying Black's condition correspond to the up-sets of this order. So by Birkhoff's duality between posets and distributive lattices the set of these linear orders is a distributive lattice. But since (as it is or it should be well-known that) majority rule coincides with the median operation in a distributive lattice, the set of these linear orders is closed under majority rule. ${ }^{23}$ In this way, Guilbaud's remarks on Black's condition also anticipated the main domain restriction in preference aggregation. Indeed, almost all restricted domains are distributive lattices defined from particular partial orders on the pairwise comparisons [Galambos, Reiner, 2008; Monjardet, 2008(b)]. Moreover, it is easy to see that Guilbaud's observation can be extended to judgment aggregation. As soon as there exists a partial order on the agenda, the set of admissible valuations corresponds to the distributive lattice of the down-sets of this poset and then majority rule always provides an admissible valuation.

\section{CONCLUSION}

In 1952, almost immediately after the publication of Arrow's seminal book in 1951, the French mathematician Georges-Théodule Guilbaud published an article in a special issue of the French review Économie Appliquée dedicated to welfare economics which anticipated both the use of ultrafilters in social choice theory and the more recent attempts to extend this area from the theory of preference aggregation to abstract aggregation theory and judgment aggregation in particular. This article published in French remained almost unnoticed, although Arrow himself acknowledged it as a "remarkable exposition of the theory of collective choice and the general problem of aggregation" in the second edition of his book [Arrow, 1963, p. 92]. This phenomenon deserves further investigation as a case of multiple discoveries due to language barriers ${ }^{24}$, but interestingly not even a partial translation of this article in 1966 was able to attract due attention ${ }^{25}$. This might be seen as evidence for deeper

\footnotetext{
${ }^{23}$ See, for instance, [Hudry et al., 2009] for the link between majority rule and the median operation in distributive lattices.

${ }^{24}$ For the significance and examples of language barriers in multiple discoveries in economics see Niehans [1995].

${ }^{25}$ The paper was sometimes quoted (for instance in [Gehrlein, Fishburn, 1978]) for a (marginal)
} 
barriers impeding scientific communication even in highly formalized areas of the social sciences.

\section{REFERENCES}

ARrow K.J., Social Choice and Individual Values, Second edition, New York, Wiley, 1963.

BLAU J.H., "Semiorders and Collective Choice", Journal of Economic Theory 21, 1975, p. $195-206$.

BROWN J.D., "Aggregation of preferences", Quarterly Journal of Economics 89(3), 1975, p. $456-469$.

COndorcet J.A.n., Condorcet: Foundations of Social and Political Theory, Aldershot, Edward Elgar, 1994.

DANIElS T.R., PACUIT E., "A General Approach to Aggregation Problems", Journal of Logic and Computation 19, 2009, p. 517-536.

DAY W.H.E., MCMORRIS F.R., Axiomatic Consensus Theory in Group Choice and Biomathematics, Philadelphia, SIAM, 2003.

DIETRICH F., LIST C., "Majority voting on restricted domains", Journal of Economic Theory 145, 2010, p. 512-543.

DIETRICH F. MONGIN P., "The premiss-based approach to judgment aggregation", Journal of Economic Theory 145, 2010, p. 562-582.

DOKOW E., HOLZMAN R., "Aggregation of binary evaluations", Journal of Economic Theory 145, 2010, p. 495-511.

FISHBURN P.C., "Arrow's Impossibility Theorem: Concise Proof and Infinite Voters", Journal of Economic Theory 2, 1970, p. 103-106.

Galambos A., Reiner V., "Acyclic Sets of Linear Orders via the Bruhat Orders", Social Choice and Welfare 30, 2008, p. 245-264.

GÄRDENFORS P., "An Arrow-like theorem for voting with logical consequences", Economics and Philosophy 22, 2006, p. 181-190.

Gehrlein W.V., Condorcet's Paradox, Series: Theory and Decision Library C, Vol. 40, Berlin, Springer, 2006.

GEHRLEIN W.V., FISHBURN P.C., "Probabilities of election outcomes for large electorates", Journal of Economic Theory 19, 1978, p. 38-49.

GuilBaud G.-TH., «Les théories de l'intérêt général et le problème logique de l'agrégation », Économie Appliquée 5, 1952, p. 501-584.

GUILBAUD G.-TH., "Theories of the general interest and the logical problem of aggregation", Lazarsfeld P.F., Henry N.W. (eds.), Readings in Mathematical Social Science, Chicago, Science Research Association, 1966, p. 262-307.

GUILBAUD G.-TH., "Theories of the general interest and the logical problem of aggregation", Electronic Journal for History and Probability 4(1), 2008.

result: the formula for the frequency of the Condorcet effect for three alternatives and a number of voters going to infinity (see also [Gehrlein 2006]). But except the very few exceptions of Murakami [1968] and Brown [1975], the main contribution of the paper remained ignored. We hope that our paper will help to rectify this oblivion. 
Hansson B., "The Existence of Group Preference Functions", Public Choice 28, 1976, p. 89-98.

HERZBERG F., "Judgement aggregation functions and ultraproducts", IMW Working Paper 405, Institut für Mathematische Wirtschaftsforschung, Universität Bielefeld, 2008.

HUdRY O., LECleRC B., MONJARDET B., BARThÉLEMY J.-P., "Metric and latticial medians", Bouyssou D., Dubois D., Pirlot M., Prade H. (éds.), Concepts and Methods of Decision Making, New York, Wiley, chap. 20, 2009, p. 763-803.

KIRMAn A.P., SONDERMAnn D, "Arrow's Theorem, Many Agents and Invisible Dictators", Journal of Economic Theory 5, 1972, p. 267-277.

KLAMLER C., ECKERT D., "A simple ultrafilter proof for an impossibility theorem in judgment aggregation", Economics Bulletin 29, 2009, p. 320-328.

KORnhauser L.A., SAGER L.G., "Unpacking the Court", Yale Law Journal 96, 1986, p. 82-117.

LEClerC B., MONJARDet B.,, 1995, "Latticial theory of consensus", Barnett V., Moulin H., Salles M., Schofield N. (eds.), Social choice, Welfare and Ethics, Cambridge, Cambridge University Press, 1995, p. 145-159.

List C., PETTit P., "Aggregating Sets of Judgments: Two Impossibility Results Compared", Economics and Philosophy 18, 2002, p. 89-110.

LIST C., POLAK B., "Introduction to judgment aggregation", Journal of Economic Theory 145, 2010, p. 441-466.

LIST C., PUPPE C., "Judgment aggregation: a survey", Anand P., Pattanaik P.K., Puppe C. (eds.), Rational and Social Choice: An Overview of New Foundations and Applications, Oxford, Oxford University Press, chap. 19, 2009, p. 457-482.

MONJARDET B., "Remarques sur une classe de procédures de vote et les théorèmes de possibilité », La décision : Agrégation et dynamique des ordres de preferences, Paris, Éditions du CNRS, 1969, p 177-185.

MONJARDET B., «Une autre preuve du théorème d'Arrow », R.A.I.R.O. Recherche opérationnelle/Operations Research 12, 1978, p. 291-296.

monjardet B., "On the use of ultrafilters in social choice theory", Pattanaik P.K., Salles M. (eds.), Social Choice and Welfare, Amsterdam, North Holland, 1983, p 73-78.

MOnjardet B., «De Condorcet à Arrow via Guilbaud, Nakamura et les 'jeux simples' », Mathématiques et Sciences humaines 163, 2003, p. 5-32.

MOnjardet, "Social choice theory and the « Centre de Mathématique Sociale »: some historical notes", Social Choice and Welfare 25, 2005, p. 433-456.

MOnJARDET B., "Liminary on Guilbaud's 1952 paper", Electronic Journal for History and Probability 4(1), 2008(a).

MONJARDET B., "Acyclic domains of linear orders: a survey", Brams S., Gehrlein W.V., Roberts F.S. (eds.), The Mathematics of Preference, Choice and Order: Essays in Honor of Peter C. Fishburn, Berlin, Springer, 2008(b), p. 139-160.

Monjardet B., G.-Th. Guilbaud et la théorie du choix social, preprint, 2010.

MURAKAmi Y., Logic and social choice, London, Routledge, 1968.

NIEHANS J., "Multiple discoveries in economic theory", European Journal of the History of Economic Thought 2, 1995, p. 1-28. 
PAUly M., VAN HeEs M., "Logical Constraints on Judgment Aggregation", Journal of Philosophical Logic 35, 2006, p. 569-585.

RUbinstein A., FISHBURn P.C., "Algebraic Aggregation Theory", Journal of Economic Theory 38, 1986, p. 63-77.

Von neumann J., morgenstern o., Theory of Games and Economic Behavior, Princeton, Princeton University Press, 1944.

WILSON R., "On the Theory of Aggregation", Journal of Economic Theory 10, 1975, p. 89-99. 